\title{
THE RELATIONSHIP BETWEEN SURFACE TREATMENTS AND CORROSION RESISTANCE OF HOT-DIP GALVANIZED STEEL
}

\author{
Amirreza Bakhtiari* \\ Department of Materials Engineering, Isfahan University of Technology, \\ Isfahan, Iran
}

Received 20.03.2014

Accepted 27.06.2014

\begin{abstract}
In this work three surface treatments such as: polishing, sand-blast and polishedoxidized have been carried out on the hot-dip galvanized coatings. The roughness and corrosion resistance of coatings have been studied. Surface morphology of coatings has evaluated by scanning electron microscope (SEM). Corrosion behavior was analyzed by salt spray cabinet test and Tafel extrapolation test. The results showed that the sample under sand-blasted treatment exhibited the highest roughness number. Tafel polarization and salt spray cabinet tests reveal the sample with great roughness number have weak corrosion resistance. Difference observed in corrosion behaviour can be explained by difference in surface roughness.

Keywords: Hot-dip galvanized coatings, Surface treatments, Roughness, Corrosion resistance
\end{abstract}

\section{Introduction}

The zinc anticorrosion protection of steels is commonly used in different environments. In the both indoor and outdoor atmospheres, automobile and electrical home appliances the zinc protection has been used due to its excellent corrosion performance. In comparison to other typical coatings zinc layer demonstrates higher adhesion and additionally ensures cathodic protection to the scratched steel. The mentioned properties come from the structure of coated layer. Typical structure of $\mathrm{Zn}$ coating is composed from $\eta, \zeta, \delta$ and $\Gamma$ phases. For analysis of the zinc-coating structure created on iron alloys the basis is the $\mathrm{Fe}-\mathrm{Zn}$ phase equilibrium diagram $[1,6]$.

Surface preparation has the essential influence on the nature of the $\mathrm{Zn}$ coating and its corrosion resistance. The most popular treatment is abrasive blasting (shot and sand blasting) and the chemical treatment [3].

In the presented work a multistage treatment - combination of these methods was applied. The aim of this work was to study the corrosion resistance of hot-dip galvanized

* Corresponding author. : Amirreza Bakhtiari, bakhtiari.amirreza@gmail.com 
coatings affected by surface preparation. Furthermore, the corrosion mechanism of coatings was discussed.

\section{Experimental procedure}

The materials used for this study were produced by MSC (Mobarake steel complex) in Iran, and had the composition listed in Table 1. The coating thickness for all samples was the same and about $35 \mu \mathrm{m}$. Production parameters such as rolling finishing temperature, coiling temperature, cold work percentage and annealing conditions were the same for all the steel sheets using in this study. All samples were degreased with alkaline detergent and toluene; they were kept in a desiccator up to starting the testes. The samples are marked based on surface treatments, polished sample (P), sandblasted sample (S-B) and polished-oxidized sample (P-O).

The samples of polishing treatment were polished using carbide papers from 80 to 1200 grit. Finally, specimens washed with ethanol and pure water, and then were polishing with $0.3 \mu \mathrm{m}$ of $\mathrm{Al}_{2} \mathrm{O}_{3}$ powder. The sandblasting treatment was applied according to Swedish standard Sa3. The oxidation treatment has carried out at $800{ }^{\circ} \mathrm{C}$ within 4 hours.

Salt spray tests were performed under the criteria established by ASTM B117 to study the galvanized specimens. The salt spray cabinet tests were conducted at room temperature.

Table 1 Chemical composition of steel substrate.

\begin{tabular}{cccccccc}
\hline $\mathrm{C}$ & $\mathrm{Si}$ & $\mathrm{Mn}$ & $\mathrm{P}$ & $\mathrm{S}$ & $\mathrm{Al}$ & $\mathrm{N}$ & $\mathrm{Fe}$ \\
\hline 0.027 & 0.004 & 0.222 & 0.007 & 0.004 & 0.058 & $30 \mathrm{ppm}$ & $\mathrm{Bal}$ \\
\hline
\end{tabular}

Cross section of the coatings was studied using scanning electron microscopy (SEM). The chemical composition of the coatings layers was determined using energy dispersive $\mathrm{X}$-ray spectroscopy (EDS).

In order to gain an understanding for correlation between surface roughness and corrosion resistance, the surface roughness profile was measured with a Hommel tester mod. Tafel polarization tests were conducted in $3.5 \% \mathrm{NaCl}$ solution at room temperature. A standard corrosion cell kit with the working electrode, two graphite counter electrodes and an $\mathrm{AgCl}$ reference electrode was used. Potentiodynamic scanning was performed by stepping the potential at a scan rate of $1 \mathrm{mv} / \mathrm{s}$ from $-250 \mathrm{mv}$ saturated calomel electrode (SCE) to $500 \mathrm{mv}$ (SCE). Salt spray cabinet test was performed according to ASTM standard B117. The salt spray test was done in $5 \% \mathrm{NaCl}$ solution at $35^{\circ} \mathrm{C}$.

\section{Results and discussion}

Fig. 1 shows the microstructure of the non-treated sample coating. Four layers could be distinguished based on their relief. In most zinc coated cases, four distinctive layers have been observed. The properties of these layers strongly depended on product parameters such as chemical compositions of zinc. Fig.2 shows the SEM micrograph of polished-oxidized (P-O) sample, the oxidized thin film may be clearly seen in this micrograph. The EDS analysis result of the coatings distinguishes four intermetallic layers (Table 2). 


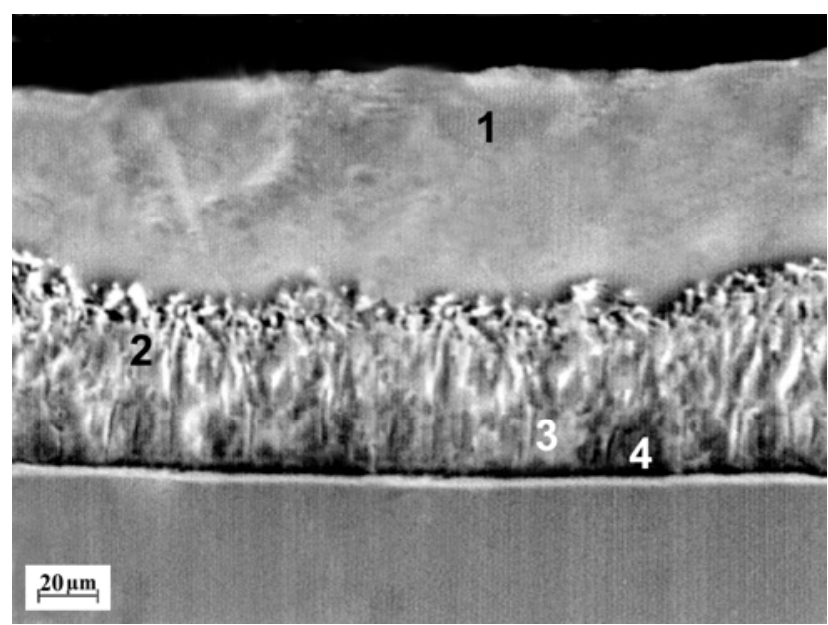

Figure 1. SEM micrograph of non-treated sample.

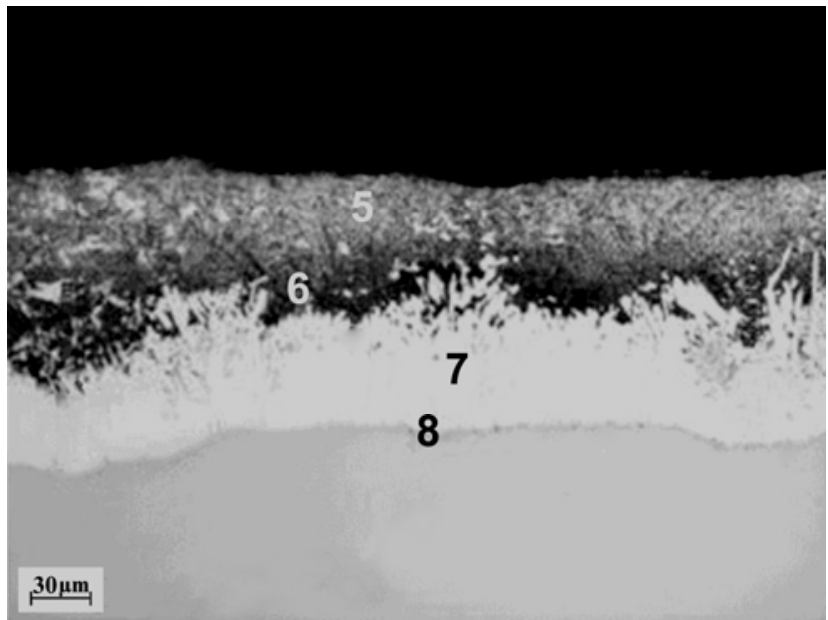

Figure 2. SEM micrograph of polished-oxidized (P-O) sample.

Starting from the substrate, this zone is in content with the ferrous substrate, probably referring to the $\Gamma$ layer phase of the Fe-Zn phase diagram. The following thicker layer, probably corresponds to the $\delta$ phase. The third layer is probably the $\zeta$, whereas the last layer possibly corresponds to $\eta$ phase (Figure 1). 
Table 2 Average results of the EDS microanalysis of the cross-section of the galvanized coatings

\begin{tabular}{llll}
\hline Phase number & Zn (wt.\%) & $\mathrm{Fe}($ wt.\%) & Phase \\
\hline 1 & 96.9 & 3.1 & $\eta$ \\
2 & 93.7 & 6.3 & $\zeta$ \\
3 & 90.6 & 9.4 & $\delta$ \\
4 & 75.6 & 24.4 & $\Gamma$ \\
5 & 97.3 & 2.7 & $\eta$ \\
6 & 93.5 & 6.5 & $\zeta$ \\
7 & 90.7 & 9.3 & $\delta$ \\
8 & 74.4 & 25.6 & $\Gamma$ \\
\hline
\end{tabular}

Figure 3 shows the correlation between surface roughness and kind of surface treatments of coatings. According to this figure, it may be seen that surface roughness of coatings can be affected by surface treatments. The sand-blast (S-B) sample shows more roughness number than polished sample $(\mathrm{P})$ and polished-oxidized $(\mathrm{P}-\mathrm{O})$ sample. The increasing in roughness number was caused by increased surface energy.

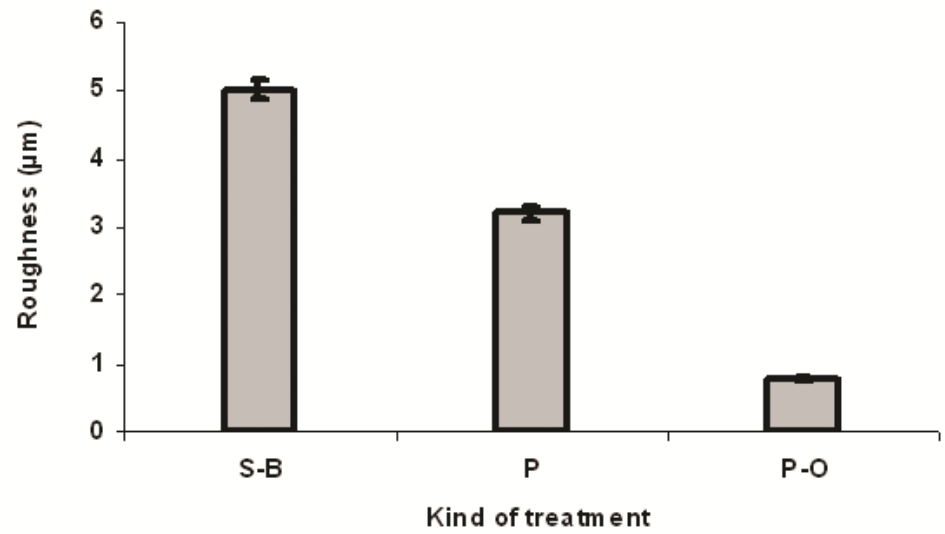

Figure 3. Relationship between kind of treatment and surface roughness.

Figure 4 shows the corrosion density $\mathrm{I}_{\text {corr }}$ of the samples as a function of the previous treatment. As it is evident, (P-O) sample shows better corrosion resistance than (P) and (S-B) samples. The $\mathrm{I}_{\text {Corr }}$ value drastically increased in (S-B) sample in compare with $(\mathrm{P}-\mathrm{O})$ sample. The $(\mathrm{P}-\mathrm{O})$ sample has been shown lowest $\mathrm{I}_{\mathrm{Corr}}$; therefore, the $(\mathrm{P}-\mathrm{O})$ sample has offered excellent function in corrosion environment. The $\mathrm{I}_{\text {Corr }}$ number for $(\mathrm{P}$ O) sample was about $0.38 \mu \mathrm{A} / \mathrm{cm}^{2}$, while the $I_{\text {Corr }}$ number for (S-B) sample was about $5.8 \mu \mathrm{A} / \mathrm{cm}^{2}$ nearly 15 times greater than $\mathrm{I}_{\text {Corr }}$ number of $(\mathrm{P}-\mathrm{O})$ sample. The high number in $\mathrm{I}_{\text {Corr }}$ values is evidence of degradation of corrosion resistance. 


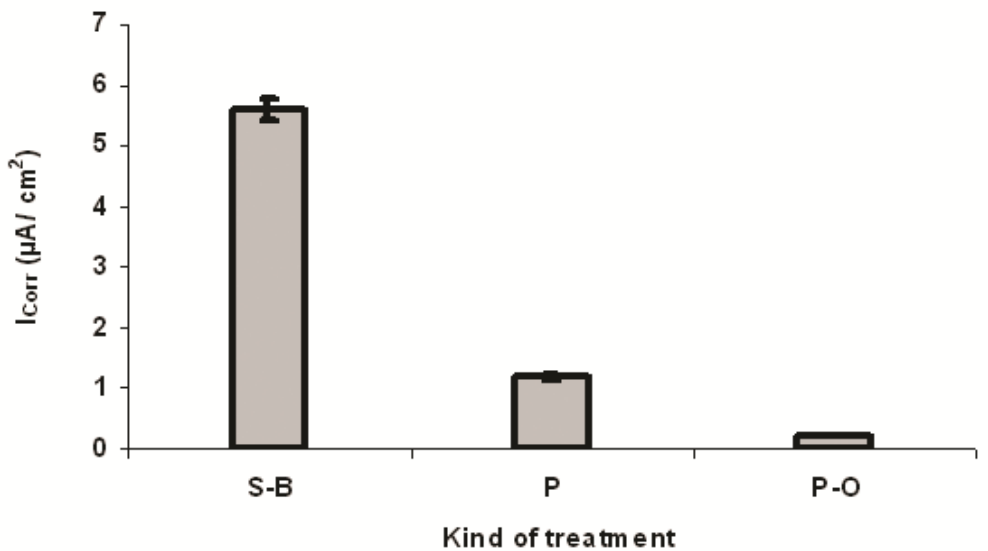

Figure 4. Relationship between kind of treatment and $I_{\text {Corr }}$.

In Fig 5 the relationship between surface treatments and time expressed in hours to reach to $5 \%$ red rust at room temperature of the samples is presented.

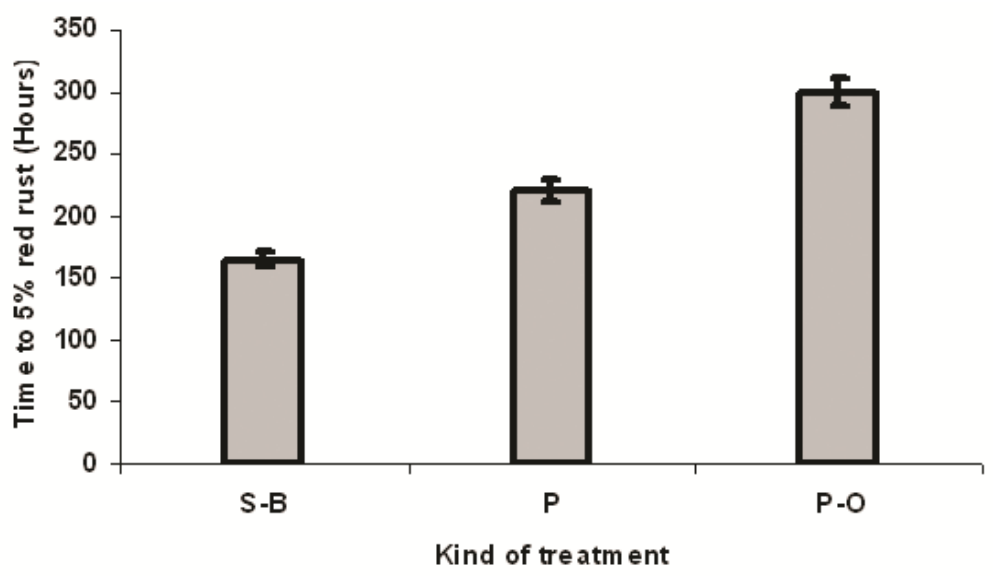

Figure 5. Relationship between kind of treatment and time to 5\% red rust.

These results approve $\mathrm{I}_{\text {Corr }}$ results. Due to an oxidation barrier film (P-O) sample indicated better corrosion resistance. The barrier film prevented corrosion environment to reach the substrate [6-7]. As it was mentioned increasing the roughness number augmented surface energy, increasing in surface energy has detrimental effect on the corrosion behaviour. In order to get some knowledge on the effect of surface roughness on the corrosion resistance of the zinc coatings systems, it is necessary to be familiar with the surface physicochemical properties. Since a high surface roughness is in equivalent to a high specific surface energy, and taking into account that a very rough metal surface has many active centers, most of the adhesion theories consider this 
surface as being very favourable for achieving a high adhesive strength with [8-9]. However, it should be remembered that machining marks on steel surface may be energetically high giving rise to regions having a particular ability to assist in the metal dissolution process. A particularly pronounced surface roughness may cause a heterogeneous energy profile in the micro regions of the steel surface. This could lead to local differences in the remaining organic coating adhesion and also to an increase of the underlying metal corrosion due to the formation of corrosive species. The optimum coating adhesion should be analyzed depending on both the type of coating and the metal surface roughness [10].

Despite advantages of sandblasting treatment such as removing old paint-and remaining previous coatings, increasing in roughness of surface coating and residual stress have detrimental effect on corrosion behaviour [11]. The corrosion resistance was degraded by the increasing surface roughness, which was confirmed with Tafel polarization test and salt spray cabinet test. Pitting corrosion on the passive oxide layer was also observed with a salt spray test [12-13].

\section{Conclusions}

Increasing the surface roughness of hot-dip galvanized coatings would results in decreasing of corrosion resistance. Although the sandblasting offers wide benefits of surface cleaning such as removing of oil, residual coatings and pollution, the increasing of roughness could lead to a decreased corrosion behaviuor. Difference observed in corrosion resistance in Tafel and salt spray cabinet tests is the consequence of the difference in the surface roughness.

In the case of oxidized-polished sample, oxide thin film as a barrier layer prevented corrosion environment to reach the steel substrate. It was observed that barrier layer was an effective parameter in increasing corrosion resistance.

\section{References}

[1] H. Hong, N. Saka, Scr. Mater. 36 (1997) 1423-1426.

[2] H. Hong, N. Saka, Acta Mater. 45 (1997) 4225-4230.

[3] N. M. Alanazi, A.M. El-Sherik, S. H. Alamar, S. Shen, Int. J. Electrochem. Sci. 8 (2013) 10350-10358.

[4] B. Yoo, K. R. Shin, D. Y. Hwang, D. H. Lee, D. H. Shina, Appl. Surf. Sci. 256 (2010) 6667-6672.

[5] B. Aksakal, M. Gavgali, B. Dikici, J. Mater. Eng. Perform. 19 (2010) 894-899.

[6] A. Bakhtiari, Metal. Mater. Eng. 18 (2012) 1-7.

[7] A. Bakhtiari, H. R. Asgari, Metal. Mater. Eng. 18 (2012) 93-101.

[8] H. Asgari, M. R. Toroghinejad, M. A. Golozar, J. Mater. Process. Technol. 198 (2008) 54-59.

[9] H. Asgari, M.R. Toroghinejad, M.A. Golozar, Curr. Appl. Phys. 9 (2007) $6777-$ 6769.

[10] H. Asgari, A. R .Bakhtiari, M. R. Toroghinejad, F. Ashrafizadeh, Ironmak. Steelmak. 35 (2008) 545-548.

[11] F. Hanna, N. Nassif, Surf. Technnol. 21 (2002) 27-37.

[12] T. Yoichi, B. Kazuhiro, Jfe. Technical. Report. 4 (2004) 55-60.

[13] M.F. Montemora, A.M. Cabrala, M.L. Zheludkevichc, M.G.S. Ferreira, Surf. Coat. Technol 9 (2006) 2875-2885. 